\title{
Aplikasi Adventure Game Berbasis Mobile Pada Komunitas Pendaki Gunung bandung
}

\author{
Angga Sopian Munawar ${ }^{1}$, Wildan Wiguna ${ }^{2}$, Tika Adilah $\mathbf{M}^{3}$ \\ ${ }^{1,2}$ Universitas Adhirajasa Reswara Sanjaya \\ e-mail: ${ }^{1}$ anggasopian696@gmail.com, ${ }^{2}$ wildan.wwg@ars.ac.id \\ ${ }^{3}$ Universitas Bina Sarana Informatika \\ e-mail: ${ }^{3}$ tika.tam@bsi.ac.id

\begin{tabular}{ccc}
\hline Diterima & Direvisi & Disetujui \\
$01-11-2021$ & $02-11-2021$ & $16-11-2021$ \\
\hline
\end{tabular}

\begin{abstract}
Abstrak - Teknologi bereperan baik sebagai media interaksi sosial, sarana edukasi, maupun sarana hiburan. Dengan menerapkan teknologi dalam kehidupan sehari-hari, diharapkan dapat membantu dan mempermudah pekerjaan. Salah satu bentuk kegiatan adalah pendakian dan petulangan, yaitu sebuah kegiatan dengan mengkombinasikan olahraga dan rekreasi yang sangat digemari oleh kalangan muda. Komunitas Pendaki Gunung Bandung (KPGB) merupakan Komunitas dengan kegiatan pendakian atau petualangan yang berperan sebagai media komunikasi dan informasi antar pegiat alam. Komunitas ini diharapkan menjadi jalur komunikasi terjalinya silaturahmi untuk membentuk kokoh rasa kekeluargaan antar sesama pendaki khususnya di Kota Bandung. Kesibukan dan padatnya jam kerja menyebabkan para anggota kesulitan dalam mengatur jadwal untuk melakukan aktivitas pendakian. Banyaknya rintangan dan tingkat kesulitan di medan pendakian, membuat banyak orang merasa takut untuk mendaki. Para pendaki yang mengalami kecelakaan dan hilang, menambah rasa takut bagi orang-orang yang ingin melakukan pendakian. Dari permasalahan yang ada perlu adanya gambaran tentang bagaimana menyelesaikan masalah ketika banyaknya aktivitas dari semua anggota yang tidak dapat melakukan pendakian. Maka aplikasi game yang bertemakan petualangan pendakian ini, dibentuk untuk memenuhi kepuasan para anggota Komunitas Pendaki Gunung Bandung, dengan pemrograman Cocos $2 d-x$ berbasis game engine Android menggunakan smartphone yang menghasilkan game petulangan pendakian yang berkarakter 2D (dua dimensi). Aplikasi ini dirancang dengan fitur yang sederhana, oleh karena itu pengguna dapat memainkan game petualangan ini dengan nyaman. Terdapat fitur yang menghubungkan langsung pengguna dengan website KPGB, yang didalamnya terdapat informasi mengenai perlengkapan mendaki. Aplikasi ini diharapkan dapat memberikan kesenangan bagi anggota Komunitas Pendaki Gunung Bandung yang tidak bisa melakukan aktivitas berpetualang atau mendaki secara langsung.
\end{abstract}

Kata Kunci : Petualangan, Komunitas, Cocos 2d-x, Android, Smartphone.

Abstrak - The development of technology is currently increasingly rapid, technology plays a role both as a medium of social interaction, a means of education, and a means of entertainment. By applying technology in everyday life, it is hoped that it can help and make work easier. One form of activity is climbing and adventure, which is an activity that combines sports and recreation which is very popular with young people. The Bandung Mountaineering Community (KPGB) is a community with climbing or adventure activities that act as a medium of communication and information between nature activists. This community is expected to be a communication line for establishing friendships to form a strong sense of kinship between fellow climbers, especially in the city of Bandung. Busy and busy working hours cause the members to find it difficult to arrange a schedule for climbing activities. The number of obstacles and levels of difficulty in the climbing field, makes many people feel afraid to climb. The climbers who had accidents and disappeared, and even died, added to the fear of those who wanted to climb. From the existing problems, it is necessary to have an idea of how to solve the problem when there are many activities from all members who cannot climb. So this game application with the theme of climbing adventure, was formed to meet the satisfaction of members of the Bandung Mountaineering Community, with Cocos $2 d-x$ programming based on the Android game engine using a smartphone that produces climbing adventure games with $2 D$ (two-dimensional) characters. This application is designed with simple features, therefore users can play this adventure game comfortably. There is also a feature that will connect users directly to the KPGB website, in which there is information about climbing equipment. This application is expected to provide pleasure for members of the Bandung Mountaineering Community who cannot carry out adventure or climbing activities directly.

Keywords : Adventure, Community, Cocos $2 d-x$, Android, Smartphone. 


\section{PENDAHULUAN}

Kegiatan petualangan atau adventure merupakan salah satu bagian penting dalam pembelajaran pendidikan jasmani. Kegiatan ini dilakukan di alam terbuka seperti kegiatan berkemah, mendaki gunung, backpacking, susur gua dan lain-lain. Saat ini kegiatan petualangan yang sedang digemari adalah mendaki gunung. Banyak orang menyukai kegiatan pendakian karena dapat memberikan pengalaman baru, teman baru, mencari pemandangan yang bagus, bahkan alasan paling menakjubkan adalah agar mengetahui bagaimana kualitas diri. Tetapi, pemahaman terhadap aktivitas berpetualang tersebut sangat diperlukan, mulai dari persiapan kesehatan fisik maupun mental. Kemudian, dalam proses kegiatan penjelajahan sangat rentan dengan kecelakan ringan ataupun serius, bahkan beresiko terhadap kematian. Sehingga pada kegiatan ini diperlukan berbagai kesiapan yang matang (Khan \& Budiningsih, 2019).

Tidak semua orang bisa pergi untuk melakukan aktivitas petualangan. Hal ini dikarenakan kesibukan sehari-hari yang penuh dengan jadwal kerja atau karena takut dengan tempat yang sangat jauh dan medan yang sulit. (Lubis, Handrizak, dkk. 2019). Kurangnya persiapan dan kesiapan dalam melakukan kegiatan berpetualang membuat seseorang tampak kesuliatan saat berpetualang di alam bebas. Kegiatan ini juga diperlukan latihan fisik gunamengurangi resiko kecelakan saat berpetualang di alam bebas. Diperlukan mental yang kuat untuk menghadapi rintangan-rintangan yang ada di alam bebas (Wijaya et al., 2017).

Komunitas Pendaki Gunung Bandung (KPGB) adalah sebuah komunitas yang dibentuk sebagai sarana komunikasi antar pegiat alam, dan bergerak dalam kegiatan sosial serta petualangan khususnya pendakian gunung. Komunitas ini juga diharapkan dapat menjadi media informasi dan sebagai titik awal terjalinnya silaturahmi untuk membentuk kokoh rasa kekeluargaan antar sesama pendaki khususnya di Kota Bandung. Tidak menutup kemungkinan bahwa komunitas ini dapat berperan aktif dalam kegiatan masyarakat.

Pada saat penulis melakukan observasi dan wawancara kepada pengurus dan anggota KPGB, didapatkan hasil bahwasanya terdapat beberapa kendala yang dialami, antara lain yaitu kesibukan dan padatnya jam kerja menyebabkan para anggota kesulitan dalam mengatur jadwal untuk melakukan aktivitas pendakian. Banyaknya rintangan dan tingkat kesulitan di medan pendakian, membuat banyak orang merasa takut untuk mendaki. Para pendaki yang mengalami kecelakaan dan hilang, bahkan meninggal dunia, menambah rasa takut bagi orang-orang yang ingin melakukan pendakian.

Dari permasalahan tersebut penulis bertujuan untuk membangun suatu aplikasi game berbasis mobile yang dapat dijadikan sebagai media hiburan bagi Komunitas Pendaki Gunung Bandung (KPGB). Kemudian pemrograman Android akan digunakan untuk membangun aplikasi pada perangkat bergerak yang mampu memfasilitasi proses implementasi dari game petualangan yang diusulkan. Sehingga tujuan utama dari penelitian ini yaitu untuk membangun aplikasi adventuregame berbasis mobile pada KomunitasPendaki Gunung Bandung.

\section{METODE PENELITIAN}

Penelitian ini diambil jenis gamifikasi, setiap kategori dalam kerangka gamifikasi dapat disampaikan sebagai permainan dan disampaikan setiap kategorinya dalam beberapa set alat bantu permainan. Pada tahap ini kerangka penelitiannya dapat membantu memahami peraturan permainan dilingkungan aktivitas berbasis game (Henry et al., 2019).

\section{Data dan Sumber Data}

Teknik atau metode pengumpulan data yang digunakan untuk mengumpulkan data primer maupun data sekunder pada pembangunan Aplikasi Game petualangan Pendakian sebagai berikut:

\section{a. Observasi}

Dilakukan pengamatan secara langsung pada Komunitas Pendaki Gunung Bandung (KPGB) dan mengamati sistem yang sedang berjalan untuk mendapatkan informasi yang bisa dijadikan sebagai data penelitian bag.i para pendaki di Kota Bandung.

\section{b. Wawancara}

Proses wawancara dilakukan dengan anggota Komunitas Pendaki Gunung Bandung (KPGB) guna mengetahuiproses berjalanya sebuah komunitas pendakian yang bertempatan di bandung.

\section{c. Studi Pustaka}

Mempelajari beberapa jurnal maupun bukubuku yang menunjang dan berkaitan dengan pembangunan aplikasi Game pendakian Gunung.

\section{Prosedur Penelitian}

Prosedur yang digunakan pada penelitian ini yaitu model ADDIE yang merupakan singkatan dari Analysis, Design, Development, Implementation, Evaluate. ADDIE merupakan model desain pembelajaran/pelatihan yang bersifat generic. (Sahfitri, Hartini, 2019). Menjadi pedoman dalam membangun perangkat dan infrastruktur program pelatihan yang efektif, dinams dan mendukung kinerja pelatihan itu sendiri. Sehingga membantu instruktur pelatihandalam pengelolaan pelatihan dan pembelajaran. Penelitian ini bertujuan untuk menghasilkan produk berupa media pembelajaran matematika game edukasi berbasis android (Dharma, 2019). sebagai berikut:

\section{a. Analyze (Analisis)}

Pada tahap analisis ini peneliti melakukan 
kegiatan sebagai berikut:

1) Analisis setiap kegiatan-kegiatan yang sering dilakukan oleh anggota KPGB.

2) Analisis sestem yang ada di KPGB.

b. Design (Perencanaan)

Tahap perencanaan ini merupakan tindak lanjut dari tahap analisis. Pada tahap ini dilakukan kegiatan seperti berikut:

1) Menetapkan kompetensi dan indikator yang akan dipelajari melalui media ini

2) Merancang design media yang dapat mendukung tercapainya kompetensi yang diinginkan

3) Menetukan tingkatan pengguna terhadap kepuasan game setelah menggunakan media yang dirancang peneliti. Perencanaan ini dilakukan agar tujuan dari penelitian ini dapat tercapai, membantu anggota untuk bias menyalurkan kegiatan di alam terbuka langsung

\section{c. Development (Pengembangan)}

Tahap pengembangan merupakan kegiatan mengubah design yang sudah dirancang ke dalam bentuk fisik berupa produk. Pada tahap pengembangan ini terjadi proses penggabungan dari berbagai media teks, gambar, animasi, audio, video, permainan, materi pelajaran dan evaluasi kedalam sebuah produk berupa game edukasi media pembelajaran metematika. Media pembelajaran yang sudah dikembangkan akan di validasi oleh tiga validator yaitu ahli media pembelajaran, ahli materi, dan ahli pembelajaran.

\section{d. Implementation (Implementasi)}

Tahap implementasi merupakan kegiatan penerapan hasil produk yang sudah dikembangkan dan telah di validasi oleh validator. Penerapan hasil produk pengembangan pada penelitian ini akan diuji cobakan kepada Komunitas Pendaki Gunung Bandung (KPGB).

\section{e. Evaluation (Evaluasi)}

Tahap evaluasi merupakan kegiatan untuk mengetahui kualitas media yang dikembangkan. Evaluasi pada model ADDIE dapat dilaksanakan pada empat tahap sebelumnya untuk memperoleh produk yang baik dan layak. Tahap evalusi di akhir model ini digunakan untukmengetahui kelayakan multimedia interaktif. Data-data yang diperoleh padaevaluasidigunakanuntukmenyempurnakanmedia yangdikembangkan.

\section{HASIL DAN PEMBAHASAN}

Pada tahap ini dilakukan beberapaanilisa fungsional game, serta kebutuhan perangkat keras dan perangkat lunak bagi pengembang aplikasi adventure game berbasis mobile (Anindito, 2016).

\section{Analisa Fungsional Game}

Dilakukan analisa kebutuhan aplikasiyang akan dibangun pada penelitian ini. Spesifikasi kebutuhan aplikasi adventuregame berbasis mobile meliputi berbagai fitur (PUSAT, n.d.) antara lain:

a. Pemain dapat melihat splash screen ketika pertama kali menjalankan game.

b. Pemain dapat melihat menu awal game.

c. Pemain dapat mengakses menu ChooseLevel yang menampilkan review level game yang telah di mainkan di menu Play atau bisa langsung memainkan aplikasi adventure game berbasis mobile mulaidari level 1.

d. Pemain dapat mengakses menu Play yang dapat langsung memainkan permainan adventure game.

e. Pemain dapat mengakses menu Setting yang meliputi.

1) Pemain dapat mengatur settinganSound

2) Pemain dapat mengatur settinganMusic

a. Pemain dapat mengakses menu more yang menampilkan informasi tentang Komunitas Pendaki Gunung Bandung (KPGB).

\section{Tahap Perencanaan (Design)}

Tahapan desain atau perancanganadalah proses yang dilakukan sebelum pengembangan sistem dimulai. Pada tahapan ini akan dijelaskan tentang karakteristik permainan dan perancangan story board dari Aplikasi Adventure Game Berbasis Mobile pada aplikasi ini.

a. Karakteristik Game

Dalam merancang sebuah sistem dalam hal ini adalah game harus berpedoman kepada karakteristik dan unsur yang terdapat pada game, yaitu:

\section{1) Format}

Adventure game yang akan dibuat terdiridari 4 elemen yaitu Choose Level, Playgame, , Setting, dan More. Pada menu Choose Level pemain bisa memilih level yang diinginkan setelah menyelesaikan semua level yang terdapat dimenu play ataupun dapat langsung memainkannya mulai dari level 1 (satu). Pada menu Playgame pemain akan bermain game sertaakan diminta untuk mengumpulkan koinkoin dan melewati rintangan mulai dari level 1 sampai level terakhir.

2) Rules

Pada adventure game, pemain harus mengumpulkan koin dan memyelesaikan satu persatu level yang telah disusun dalam bentuk tempat dan diberi nama gunung pada menu Play. Setelah mengumpulkan koin dan menyelesaikan semua level pemain dapat memilih level pada menu Choose Level pada adventuregame. 
3) Policy

Ketika pemain sedang mengumpulkan koin dan melewati rintangan yang ada di dalam aplikasi adventure game, maka pemain dapat langsung menuju ke level berikutnya, selanjutnya jika pemain tidak bisa mengumpulkan koin serta tidak bisa melewati rintangan pemain akan mengulangi aplikasi adventure game hingga dapat mengumpulkan koin danmelewati rintangan dengan benar setelah itu pemain dapat mengakhiri permainan atau bisa lanjut ke level berikutnya

4) Scenario

Dalam menjalankan game ini penulismenentukan scenario yang akan dimainkan oleh pengguna. Pada menu utama terdapat menu setting dan menu more serta choose level untuk memilih level yang sudah di mainkan sebelumnyapada menu play ataupun dapat langsung memainkan nya dari mulai level 1. Selain itu pemain dapat bermain aplikasi adventure game, pemain akan dimintamenyelesaikan tantangan dan mengumpulkan koin sebanyak munkin sehinga mencapai target agar bisa melanjutkan ke level berikunya.

5) Events/Challenge

Pada permainan ini tantangan yang diberikan adalah rintangan-rintangan dalam perjalanan pengumpulan koin pada setiap level yang ada. Rintangan yang di berikan berupa jebakanjebakan, hewan, jurang serta bebatuan dan mengumpulkan koin. Jika rintangan telah berasil dilalui dan koin sudah terkumpul maka pemain dapat berpindah ke levelberikutnya atau mengakhiri permaiananya. Tangtangan yang diberikan agar pemain dapat mengasah kemampuan dan keterampilan serta logika sambil bermain.

6) Roles

Didalam aplikasi adventure game telah rancang dan disediakan rintangan, pemain harus melewati rintangan-rintangan dan mengumpulkan koin pada setiap level yang ada.

7) Decission

Keputusan yang dapat dibuat pemain didalam aplikasi adventure game ini adalah pemain mengumpulkan koin sesuai dengan target dan melewatirintangan-rintangan agar bisa melanjutkan ke level berikutnya

8) Levels

Permainan yang telah dibuat terdiri dari beberapa level dan tingkat kesulitannya. Pemain harus dapat mengumpulkan koinsebanyak munkin dan melewati rintangan-rintangan sehinga tercapai target agar dapat berpindah tempat mulai dari level 1 sampai level berikutnya

9) Simbol

Sebagai penunjuk ke state berikutnya atau ke state sebelumnya digunakan tanda panah. Selain itu juga terdapat tombol-tombol pada menu yang berupa gambar yang digunakan untuk menuju ke menu-menu yang disediakan. Serta ada tombol pause untuk menghentikan dan jeda pada adventure game.

\section{b. Perancangan Storyboard}

Pada perancangan atau desain storyboard berisi pembahasan mengenai alurcerita dari aplikasi adevnture game yang akan disampaikan dengan tulisan dan gambar pada penelitian ini.

1) Storyboard Splash Screen

Pada storyboard yang digunakan untuk perancangan halaman splash screen menampilkan sketsa ketika pertama kali game yang dimainkan yang dapat dilihat pada Tabel 1.

Tabel 1. Storyboard of Splash Screen

\begin{tabular}{|l|c|c|}
\hline \multicolumn{1}{|c|}{ Visual } & Sketsa & Audio \\
\hline $\begin{array}{l}\text { Pada splash } \\
\text { screen }\end{array}$ & \\
menampilkan \\
antar muka \\
ketika \\
pertama kali \\
aplikasi \\
adventure \\
game \\
dijalankan
\end{tabular}

Sumber: Penelitian (2020)

Pada Tabel 1 menunjukkan storyboard yang menampilkan splash screen ketika pertama kali aplikasi adventure game dijalankan. Splash screen yaitu tampilan pertama dari aplikasi adventure game yang muncul sementara sebelum masuk ke halaman utama. Dengan kata lain, splash screen ini muncul saat aplikasi game sedang diluncurkan. Pada tampilanini terdapat elemen kontrol grafis yang terdiri dari jendela yang berisi gambar atau logo Komunitas Pendaki Gunung Bandung (KPGB) yang dikembangkan. Halaman splash adalah halaman pengantar di aplikasi adventure game. 
2) Storyboard Halaman Utama

Pada menu halaman utama terdapat beberapa menu yaitu, menu play untuk lanjut ke menu berikutnya, menu setting untuk mengatur pada game musik dan game sound kemudian ada menu more yaitu akan menampilkan informasi website dari komunitas Pendaki Gunung Bandung (KPGB) yang didalamnya ada berbagai fiture seperti profile dari komunitas pendaki gunung bandung serta menjual merchande peralatan dan pelengkapan kegiatan petualangan atau pendakian seperti pada Tabel 2.

Tabel 2. Storyboard Halaman Utama

\begin{tabular}{|l|l|l|}
\hline \multicolumn{1}{|c|}{ visual } & Sketsa & \multicolumn{1}{c|}{ Audio } \\
\hline Pada & & PTMo \\
halaman & & delsou \\
utama & & nd \\
terdapat & & \\
beberapa & & \\
menu yaitu & & \\
menu setting & & \\
menu play & & \\
dan menu & & \\
more. & & \\
\hline
\end{tabular}

Sumber: Penelitian (2020)

Pada Tabel 2. menunjukan storyboard menu utama terdapat beberapa menu yaitu, menu setting, menu play, menu more. Pada Menu setting untuk mengaturgame musik dan game sound sebelum memainkan aplikasi adventure game dimulai. Menu play yaitu menu untuk menunjukan ke halaman berikutnya menumore terdapat informasi tentangKomunitas Pendaki Gunung Bandung (KPGB)

\section{3) Storyboard Choose Level}

Pada storyboard menu choose level terdapat review level yang sebelumnya dimainkan di menu play game, atau dapat memainkannya langsung dari level 1 terlebih dahulu. Seperti pada Tabel 3

Tabel 3. Storyboard Choose Level

\begin{tabular}{|c|c|c|}
\hline visual & Sketsa & Audio \\
\hline $\begin{array}{lr}\text { Pada } & \text { menu } \\
\text { choose } & \text { level } \\
\text { terdapat } & \text { review } \\
\text { yang sebelumnya } \\
\text { dimainkan } \\
\text { dimenu }\end{array}$ & 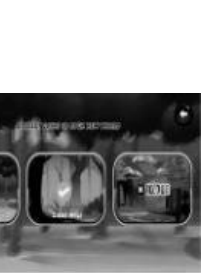 & \\
\hline
\end{tabular}

Sumber: Penelitian (2020)
Pada Tabel 3. menunjukkan story board dari menu choose level terdapat reviewlevel yang sebelumnya dimainkan dimenu play, atau dapat memainkannya langsung dari level 1 (satu) terlebih dahulu. Sehingga pemain dapat membuat semua level dari menu choose level terbuka terlebih dahulu.

\section{4) Storyboard Play Game}

Pada menu play game terdapat karakter pemain yang sedang berpetualang pengumpulkan koin, setelah setalah koin terkumpul maka pemain dapat melanjutkan ke level selanjutnya. Seperti pada tabel 4.

Tabel 4. Storyboard Play Game

\begin{tabular}{|c|c|c|}
\hline visual & Sketsa & Audio \\
\hline $\begin{array}{l}\text { Pada menu } \\
\text { play game } \\
\text { terdapat } \\
\text { karaktergame } \\
\text { yang sedang } \\
\text { berpetualang } \\
\text { mengumpulkan } \\
\text { koin }\end{array}$ & 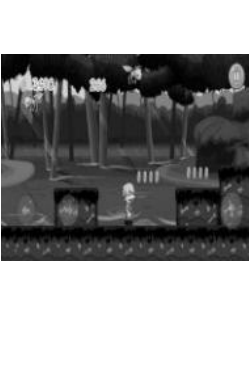 & $\begin{array}{c}\text { PT } \\
\text { model } \\
\text { Sound } \\
\text { _id3 }\end{array}$ \\
\hline
\end{tabular}

Sumber: Penelitian (2020)

Pada Tabel 4. menunjukkan storyboard menu play game terdapat karakter yang sedang berpetualang mengumpulkan koin dan melwati rintangan-rintangan, setelah koin terkumpul sesuai target maka pemain dapat melanjutkan ke level selanjutnya dan jika pemain tidak dapat mengumpulkan koin tau mati karena tidak bisa melewati rintangan maka akan kembali mengulangi lagi adventure game atau keluar pada game tersebut

\section{5) Storyboard Setting}

Pada menu setting pemain dapat mengatur beberapa fitur dari aplikasi adventure game. Pengaturan tersebutmeliputi pengaturan sound untuk mengatur suara tombol, pengaturanmusic untuk mengaktifkan ataumenonaktifkan suara musik, ketika pengguna memainkan adventure game. Pengaturan storyboard pada aplikasi aplikasi adventure game dapat dilihat pada tabel 5. 
Tabel 5. Storyboard Setting

\begin{tabular}{|l|c|c|}
\hline \multicolumn{1}{|c|}{ visual } & Sketsa & Audio \\
\hline Pada menu & & \\
setting \\
pemain dapat \\
game tombol \\
musik dan \\
tombol sound
\end{tabular}

Sumber: Penelitian (2020)

Pada Tabel 5. storyboard menu setting pemain dapat mengatur beberapa fitur dari aplikasi adventure game. Pengaturan tersebut meliputi pengaturan sound untuk mengatur suara tombol, pengaturan music untuk mengaktifkan atau menonaktifkan suara musik, dan ketika pengguna memainkan adevntura game. Pengaturan storyboard pada aplikasi adventure game.

\section{6) Storyboard More}

Pada storyboard menu more terdapat informasi pada Komunitas Pendaki Gunung Bandung (KPGB). Informasi pada menu about tersebut meliputi nama profile Komunitas Pendaki Gunung Bandung (KPGB), foto-foto kegiatan Komunitas Pendaki Gunung Bandung (KPGB), artikel-artikel mengenai kegiatan alam bebas dan menjual merchandase Komunitas Pendaki Gunung Bandung (KPGB). Seperti pada Tabel 6.

Tabel 6. Storyboard More

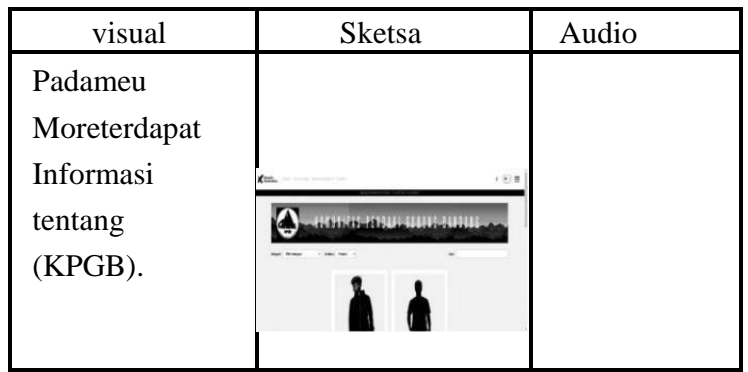

Sumber: Penelitian (2020)

Pada Tabel IV.6 menunjukkan perancangan storyboard bagi halaman more yang terdapat informasi tentangalamat basecamp Komunitas Pendaki Gunung Bandung (KPGB), foto-foto kegiatan, artikel tentang Komunitas Pendaki Gunung Bandung, artikel pralatan yang biasa dibawa saat melakukan petualangan dan artikel tempat wisata alam serta menjual merchande peralatan dan pelengkapan kegiatan petualangan atau pendakian.

\section{State Transition Diagram}

Adastatetransitiodiagrammengambarkan pemodelam sifatnya ketergantugan terhadap sistem dan tampilan tatap muka pada sistem mobile. Pada pemodelan ini juga digunakan oleh penulis dalam menjelaskan alur-alur dari aplikasi adventure game berbasis mobile.

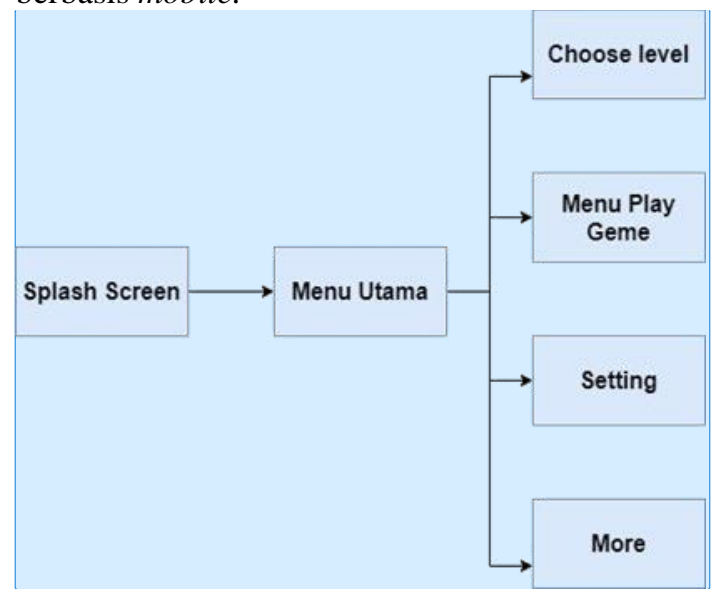

[Asus1]

Sumber: Penelitian (2020)

menampilkan splash screen ketika pertama kali aplikasi adventure game dijalankan. Splash screen yaitu tampilan pertama dariaplikasi adventure game yang muncul sementara sebelum masuk ke halaman utama. Dengan kata lain, splash screen ini muncul saat aplikasi game sedang diluncurkan. Pada tampilan ini terdapat elemen kontrol grafis yang terdiri dari jendela yang berisi gambar atau logo KPGB.

\section{Tahap Penerapan (Implementation)}

Pada tahapan ini menerapkansemua yang telah dibuat pada tahapan sebelumya. Jadi hasil akhir dari tahapan ini adalah sebuah aplikasi adeventure game berbasis mobile yang telah siap digunakan namun masih ada tahapan lagi sebelum dapat di gunakan secara umum. Terdapat beberapa tombol yang dihadirkan pada aplikasi adventure game yang dibangun antara lain:

a. Tombol "Choose Level" berfungsi untuk memilih riview level permainan yang ingin dimainkanatau dapat langsung memainkannya dari mulai level 1 .

b. Tombol "Play" berfungsi untuk memulai permainan.

c. Tombol "Setting" berfungsi untuk mengatur tampilan, Sound, Music.

d. Tombol "more" berfungsi untukmenampilkan informasi tentang Komunitas Pendaki Gunung Bandung (KPGB).

Penerapan userexperience berfungsiuntuk memberikan kemudahan kepada pengguna dalam menggunakan aplikasi adventure game berbasis mobile. Tampilanantarmuka diawali dengan tampilan halamanutama yang memiliki empat fungsi 
tombol yaitu:

a. UserExperience Splash Screen

Pada User Experience (UX) dari splashscreen menampilkan pertama kaliaplikasi adventure game dijalankan yang dapat dilihat pada ambar 1 .

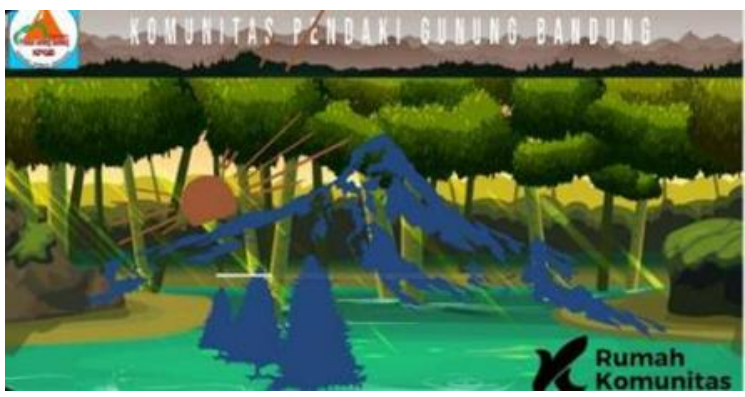

Sumber: Penelitian (2020)

Gambar 1. Tampilan UX Splash Screen

Pada Gambar 1. menjelaskan UserExperience (UX) dari menu splash screenyang menampilkan pertama kali menjalanakn aplikasi adventure game. Dengan kata lain, splash screen ini muncul saat aplikasi game sedang diluncurkan.

b. User Experience Menu Utama

Pada pengalaman pengguna terhadap menu utama yang menampilkan halaman utama dari game yang dapat dilihat pada Gambar 2.

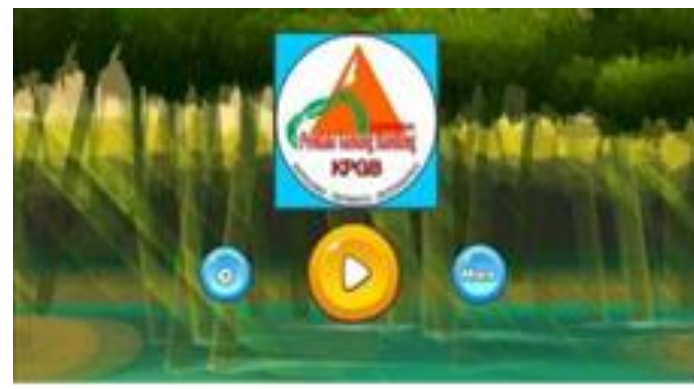

Sumber: Penelitian (2020)

\section{Gambar 2. Tampilan UX Menu Utama}

Pada Gambar 2 menjelaskan UserExperience (UX) dari manu utama yangmenampilkan halaman dari game Math Fruits terdapat 3 tombol yaitu, tombol Play untuk menuju kepermainan dari aplikasiadventure game, setting untukmenampilkan halaman setting dan pemain dapat mengatur game dengan tampilan tombol sound, tombol music. More terdapat informasi tentangKomunitas Pendaki Gunung Bandung (KPGB).

c. User Experience Choosen Level

Pada pengalaman pengguna terhadap Choose Level yang menampilkanbeberapa tampilan level mulai dari level 1 sampai 3. atau dapatmemainkan nya langsung dari level 1 (satu) terlebih dahulu. Terdapat dilihat pada gambar 3 .

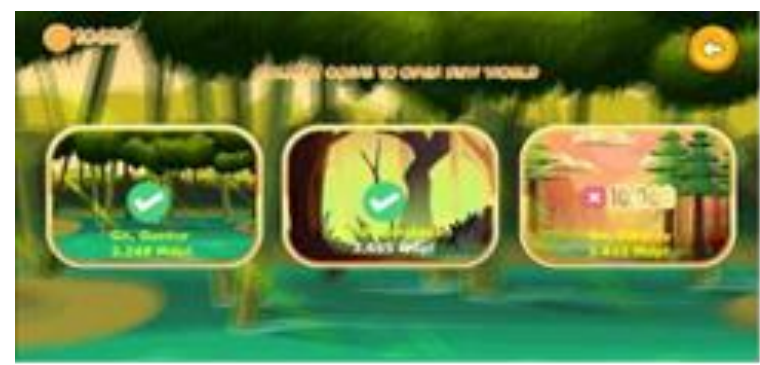

Sumber: Penelitian (2020)

Gambar 3. Tampilan UX Choose Level

Pada Gambar 3 menjelaskan UserExperience (UX) dari menu Choose Level untuk mereview level yang sebelumnya dimainkan oleh pemain yang terdapat dimenu play, atau dapat memainkan nya langsung dari level 1 (satu) terlebih dahulu. Sehingga pemain dapat membuatsemua level dari menu choose level terbuka.

d. User Experience Play Game

Pada tombal Play user dapat langsung memainkan game yang harus di isi oleh pemain, setelah petualangan baru dimulai yang harus mengumpulkan koin dan melewati rintangan serta melanjutkan ke level selanjutnya. Dapat dilihat padagambar 4 .

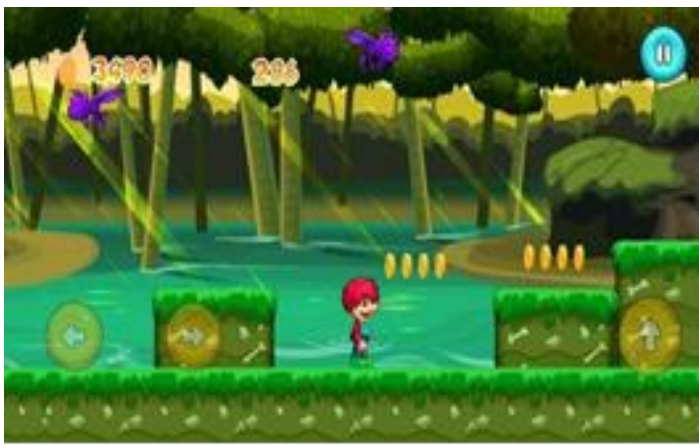

Sumber: Penelitian (2020)

Gambar 4. Tampilan UX Play Game

Pada Gambar 4 menjelaskan UserExperience (UX) dari menu play gameterdapat karakter yang sedang mengumpulkan koin dan melewati rintangan, setelah koin terkumpul sesuai target maka pemain dapat melanjutkan ke level selanjutnya dan jika pemain tidakdapat mengumpulkan koin tau mati karena tidak bisa melewati rintangan.

e. User Experience Menu Setting Pada pengalaman pengguna terhadap tombol 
setting terdapat 2 tampilan yaitu, Sound, Music, seperti pada gambar 5 .

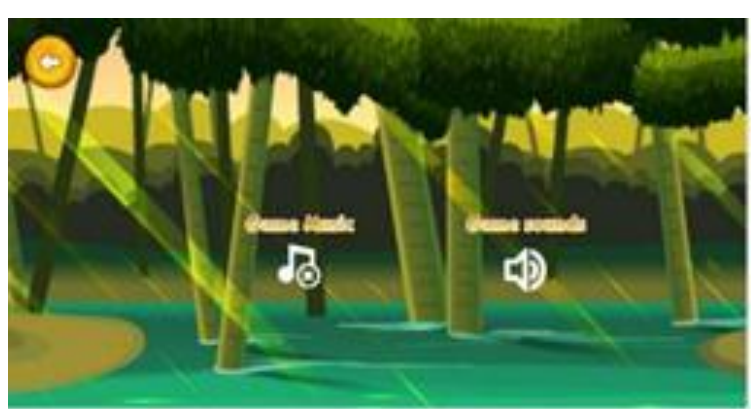

Sumber: Penelitian (2020)

Gambar 5.Tampilan UX Menu Setting

Pada Gambar 5 menjelaskan UserExperience (UX) dari menu Setting untukmengatur game dengan tampilan tombol sound untuk mengatur suara game, tombol music untuk mengatur music dari game.

\section{f. User Experience Menu More}

Pada User Experience (UX) more terdapat informasi tentang Komunitas Pendaki Gunung Bandung (KPGB) yang terdapat pada Gambar 6.

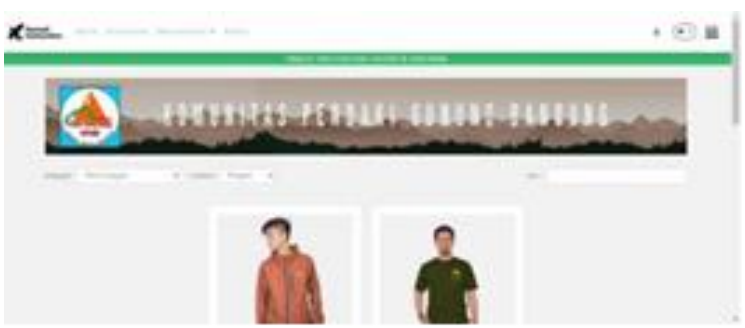

Sumber: Penelitian (2020)

Gambar 6.Tampilan UX Menu More

Pada Gambar 6 menjelaskan User Experience (UX) dari menu more terdapat informasi tentang alamat basecamp Komunitas Pendaki GunungBandung (KPGB), artikel tentang komunitas pendaki gunung bandung, artikel pralatan yang biasa dibawa saat melakukan petualangan dan menjual merchande peralatan dan pelengkapan kegiatan petualangan serta marchandes lainya.

\section{Tahapan Evaluasi (Evaluation)}

Aplikasi yang telah dibuat, selanjutnya yaitu diuji melalui teknik pengujian perangkat lunak yang menggunakan pengujian white box testing.

a. White Box Testing

Pengujian White Box adalah salah satu cara untuk menguji suatu aplikasi atau software dengan cara melihat modul untuk dapat meneliti dan menganalisa aplikasi game (Kusuma \& Setiawan,
2018) pada Gambar berikut.

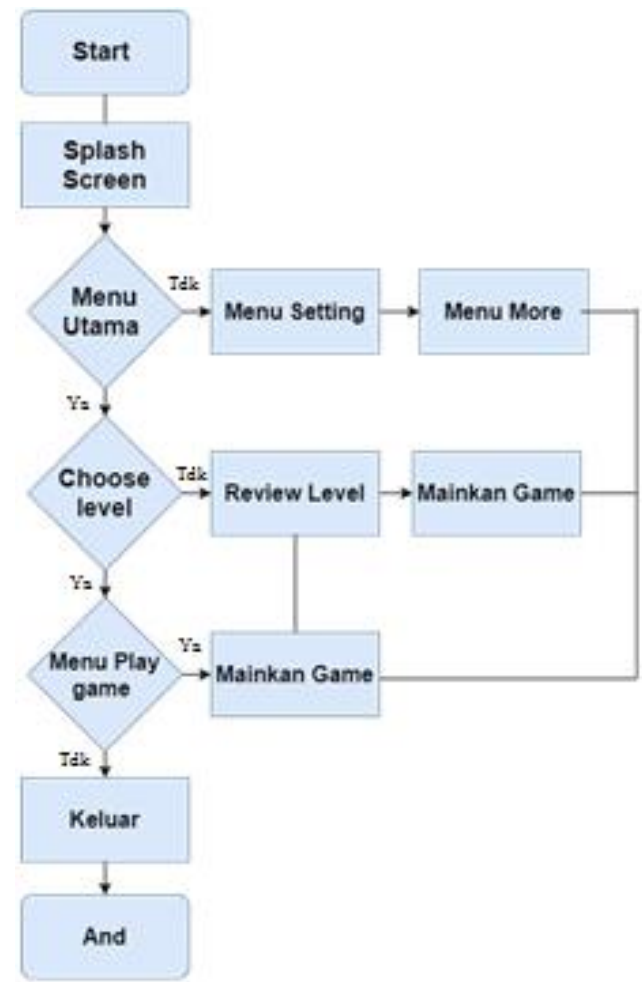

Sumber: Penelitian (2020)

Gambar7.Bagan Alir Game

Pada grafik alir pengujian white box yang disarkan pada pengecekan terhadap detail rancangan aplikasi adventure game dapat dilihat pada Gambar Berikut.

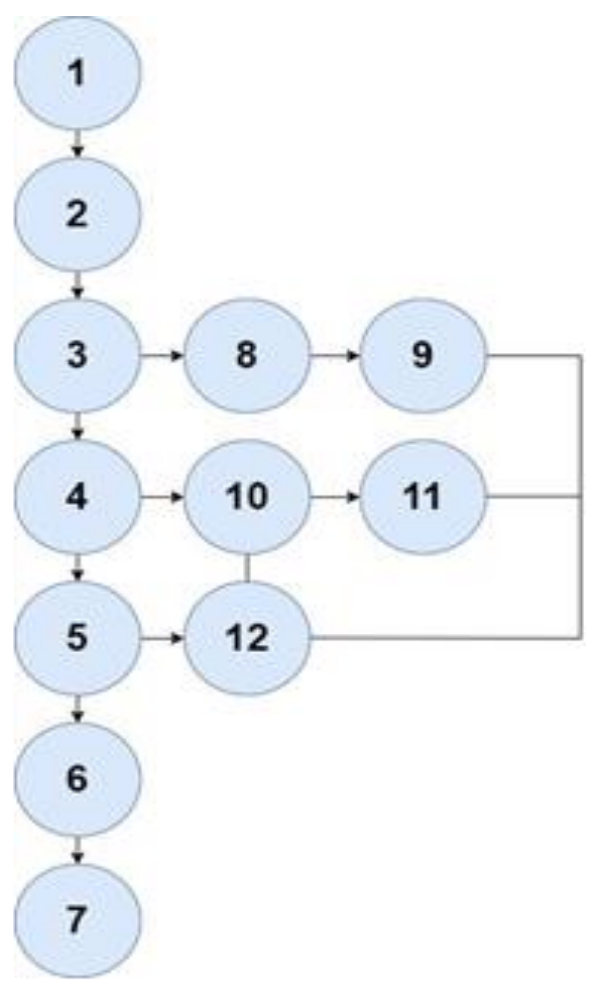

Sumber: Penelitian (2020) 


\section{Gambar 8.Grafik Alir Game}

Pada Gambar 8 dapat dihitung kompleksitas siklomatis dari grafik alir untukwhite box testing yang dapat diperolehdengan perhitungan berikut ini:

$V(G)=12-12+2=2$

$V(G)<10$

Dari hasil perhitungan tersebut terlihat bahwa aplikasi Math Fruits yang dikembangkan telah memenuhi persyaratan kelayakan dari kompleksitas siklomatisnya, dengan kata lain dapat dikatakan sebagai aplikasi yang user friendly atau mudah digunakan.

\section{b. Hasil Pengolahan Data Kuisioner}

Dilakukan pembagian angket kuesioner yang terdiri dari 10 pertanyaan kepada anggota komunitas dan pendaki. Kuisioner diberikan kepada 40 anggota komunitas setelah aplikasi game dijalankan. Kemudian kuisioner dibagikan kepada 20 pendaki gunung yang bukan anggota Komunitas Pendaki Gunung Bandung (KPGB) tentang aplikasi adventure game berbasis mobile pada Komunitas Pendaki Gunung Bandung (KPGB).

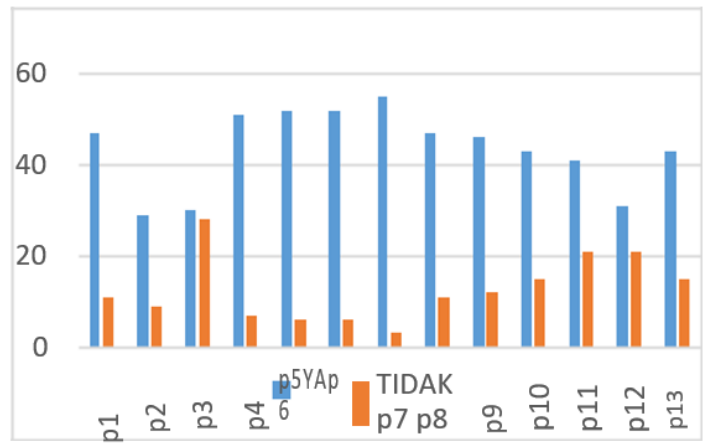

Sumber: Penelitian (2020)

\section{Gambar 9.Tampilan Grafik Kuisioner}

Dari grafik hasil kuesioner pada Gambar 8 dapat diambil kesimpulan bahwa sebagian besar anggota komunitas dan pendaki gunung dapat membantu terhadap aplikasi adventure game berbasis mobile, serta dapat membantu para anggota Komunitas Pendaki Gunung Bandung (KPGB) yang tidak bisa melakukan petualangan.

\section{KESIMPULAN}

Simulasi petualangan pendakian yang telah diaplikasikan menjadi sebuah game menggunakan prinsip-prinsip dan elemen utama dari suatu permainan pada alur petualangan di Komunitas Pendaki Gunung Bandung (KPGB). Dari hasil pembahasan gamifikasi yang telah dilakukan padapenelitian ini, maka dapat diambil kesimpulan sebagai berikut:

1. Gamifikasi petualangan pendakian mampu memenuhi kerinduan terhadap aktivitas petualangan di sela-sela padatnya kesibukan kerja. Hal ini dikarenakan para penggemar kegiatan petualangan dapat bermain game tanpa harus meluangkan waktu yang relatif banyak.

2. Aplikasi game yang dibangun telah berfungsi sebagai fasilitas tambahan bagi para anggota komunitas yang belum mempunyai kesiapan fisik maupun mental dalam memacu adrenalin terhadap petualangan. Pada aplikasi adventuregame telah dilengkapi dengan simulasipetualangan yang mampu memacu adrenalin terhadap petualangan pendakian seperti melewati rintangan jurang, melewati hewan buas, dan bebatuan yang menghalangi petualangan.

3. Aplikasi adventure game yang diimplementasikan telah berhasil dibangun menggunakan mobileprogramming pada platform Android.Aplikasi tersebut berhasil dipasang pada smartphone dengan sistem operasiAndroid yang pada dasarnya dimiliki oleh para anggota Komunitas Pendaki Gunung Bandung.

\section{REFERENSI}

Anindito, H. (2016). Faktor-Faktor yangMempengaruhi Masyarakat Untuk Menghuni Apartemen Menengah Atas Surabaya. Institut Teknologi Sepuluh Nopember.

Bakhri, Syamsul (2019). Animasi Interaktif Pembelajaran Huruf dan Angka Menggunakan MetodeADDIE.https://ojs.unpkediri.ac.id/inde x.php/intensif/article/view/12666/1158

Dharma, S. W. C. (2019). SEBATIK Volume23 Nomer 2 Desemeber 2019. PusatPenelitian dan Pengabdian

Masyarakat(P3M).https://books.google.co.id/b ooks?id=JarEDwAAQBAJ

Henry, P., Setyosari, P., \& I Nyoman Sudana Degeng. (2019). Teori danimplementasi teknologi pendidikan (Era Belajar Abad 21 dan Revolusi Industri 4.0. Seribu Bintang.https://books.google.co.id/books?id=v MCyDwAAQBAJ

Khan, I. A., \& Budiningsih, M. (2019).PERSEPSI SISWA SMA NEGERI SE-KECAMATAN DUREN SAWIT TERHADAP MATERI PENJELAJAHAN GUNUNG DALAM MATA PELAJARAN PENDIDIKAN JASMANI. Jurnal Olahraga Rekreasi, 1(1), $58-63$ 
Kusuma, A. P., \& Setiawan, B. (2018).WHITE BOX TESTING PADA SISTEM PEMESANAN DESAIN SABLON BERBASIS WEB. Jurnal Teknika, 10(2), 1040-1044.

Lubis, Ratika Rizka. Handrizal, dkk. (2019). Analisis Metode Profile Matching dalam Merekomendasikan Tujuan Wisata Pendakian. http://tunasbangsa.ac.id/seminar/index.php/sen aris/article/view/67

PUSAT, I. D. I. C. (n.d.). PERANCANGANMIXED USE MAL, HOTEL DAN CONVENTION CENTER DENGAN PENDEKATAN.
Sahfitri, Hartini (2019). Metode ADDIE Pada Aplikasi Interaktif Mengenal Bagian Tubuh Manusia Dua Bahasa Untuk Anak Sekolah Dasar.http://ejournalbinainsani.ac.id/index.php /ISBI/article/view/1085/955

Wijaya, I. D., Wibowo, D. W., \& Ramadhan, N. M. (2017). Pengembangan Game Petualangan 3D Jelajah Puncak Mahameru Dengan Penentuan Jalur Pendakian Terbaik Menggunakan Algoritma a. Seminar InformatikaAplikatif Polinema. 